\title{
PID Reference Tracking Control for Nonlinear Active Vehicle Suspension System
}

\author{
Olurotimi A. Dahunsi ${ }^{\mathrm{a},{ }^{*}}$ and Jimoh O. Pedro ${ }^{\mathrm{b}}$

\begin{abstract}
${ }^{a}$ Mechanical Engineering Department, Federal University of Technology, P. M. B. 704, Akure, Ondo State, Nigeria Private Bag 03, WITS 2050, Johannesburg, South Africa

*Corresponding Author: tundedahunsi@gmail.com; oadahunsi@ futa.edu.ng
\end{abstract} \\ ${ }^{\mathrm{b}}$ School of Mechanical, Industrial and Aeronautical Engineering, University of the Witwatersrand, 1 Jan Smut Avenue,
}

\begin{abstract}
In spite of the superior performance of active vehicle suspension system (AVSS), its implementation on large commercial scale is impaired by challenges related to controller design and hardware. PID feedback control loop with a cascade of two other PID sub-loops for force control and spool-valve displacement control has been employed in this work. The additional PID controller (in the inner loops) did not only help in stabilizing the actuator dynamics, they also increased the chances of better AVSS performance by the addition of tuning variable and the close tracking of a sinusoidal reference input. The control voltage, spool-valve displacement and suspension travel signals were within required range throughout but the maximum allowable actuator force value and control voltage was marginally exceeded at the peak of the humps.
\end{abstract}

Keywords: Active vehicle suspension system, PID control, controller design, actuator dynamics, spool valve.

\section{Introduction}

Growing advances in the field of electronics, instrumentation, terramechanics, vehicle dynamics and control have created oppurtunities for implementation of active vehicle suspension systems in commercial, luxury, military and construction vehicles today ${ }^{(1,2)}$.

Electrohydraulic actuators are the most viable source of actuator force for AVSS applications because of advantages like, lower cost, high power-to-weight ratio, fast response, high stiffness and good load bearing capability, the dynamics due to its coupled interaction with the suspension is highly nonlinear. Many of the documented works have neglected consideration of actuator dynamics in their analysis for this reason ${ }^{(3,4,5,6)}$. Introduction of sub-loop for the feedback control of the command force in AVSS control design has been shown to contribute immensely to the stability and tracking in the presence of deterministic road disturbances ${ }^{(3,4,6)}$.

Cascaded PID feedback control loops are employed in this work for disturbance rejection (originating from the uneven road terrain). The inner loops are for feedback control of actuator force and actuator spool-valve position control, while the main control output variable is suspension travel. The effectiveness of the electrohydraulic actuator depends on accurate positioning of its spool valve. In the past, spool-valve displacement has been ignored because of instrumentation and cost challenges. Servo-valves assemblies with mounted miniaturised or embedded Linear Variable Differential Transformer (LVDT) are now available ${ }^{(7,8,9)}$.

Controller design works for AVSS are well documented with different methods used cutting across the entire spectrum of control methods. This includes optimal control methods, that are relatively well developed, robustness and their stability are readily established; nonlinear and intelligent control methods ${ }^{(10,11)}$.

Popular nonlinear control schemes like feedback linearization, backstepping and sliding mode control have been employed in AVSS design. While their control performances were good in the face of the complex and inherent nonlinearity that characterise AVSS, they often suffer setback at the point of implementation, due to degradation of system performance caused by chattering $^{(12,13,14)}$.

PID control loop remains the most used industrial controller because of its simple structure and relative ease of tuning either intuitively or by use of tuning methods ${ }^{(15,16,17,18)}$. Other more complex controllers sacrifice this simplicity and computational ease for better performance. A prospect of improved system performance exists for PID when combined with other controllers or 
tuned using computational intelligence techniques ${ }^{(19,20)}$. The combination can also improve robustness to parameter variations and better tuning could eliminate its requirement of high loop gains ${ }^{(4,17,21,22)}$. Finally, PID is more effective at adjusting system parameters like overshoot, rise and settling time ${ }^{(5,21)}$

Although it is customary to set up vehicle suspension control design problem in the regulatory control problem mode $^{(5,22)}$. The degree of deviation of the controlled output of the system from a fixed desired level is focus in spite of the disturbance input. In this work, the focus is the tracking of a sinusoidal reference trajectory.

The rest of the paper is structured as follows: The next section presents a brief description of the physical model, the mathematical and road disturbance input models. The third section highlights the system specifications and evaluation criteria, while the fourth section presents the controller design. The fifth section presents the discussion of results and is followed by the concluding remarks in the last section.

\section{System Modelling}

Figure 1 presents the generic active vehicle suspension system (AVSS) feedback control loop. The system consists of a controller issuing the command input to the actuator to generate a manipulating signal.

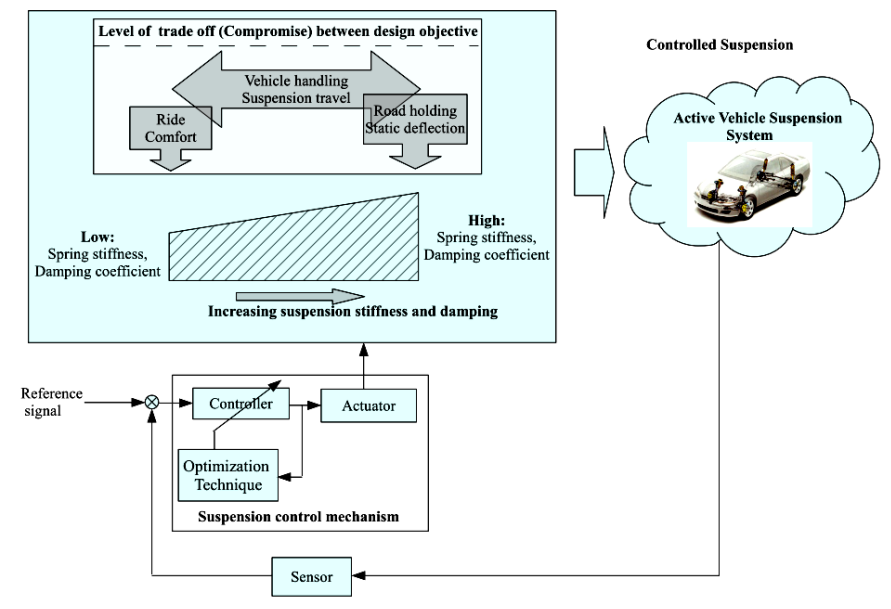

Fig. 1 Generic AVSS Feedback Control Loop

AVSS responds dynamically to road disturbance inputs by inducing relative motion between the body and the wheel through the force generated by the servo-hydraulic actuator. Obtaining the appropriate control voltage for the actuator includes an optimal trade-off between the design objectives in the presence of road disturbance inputs. The success of this process yields a suspension system that is adaptive to the road disturbance and other operating conditions.

The physical system used for this investigation is a 2DOF, quarter-car independent suspension model shown in Figure 2 . This model readily captures the body heave and wheel hop vibration mode. The sprung mass (chassis) is represented by $m_{s}$, unsprung mass (wheel) $m_{u} . k_{s}$ and $k_{t}$ are the suspension and wheel stiffnesses respectively. $b_{s}$ is the damping coefficient of the suspension system, $F$ is the actuator force, $x_{1}$ and $x_{2}$ are the vertical displacements of the chassis and wheel respectively, while $\mathrm{w}$ is the road disturbance input.

\subsection{Mathematical Modelling}

The controlled variable is represented by the suspension travel $\left(x_{1}-x_{2}\right), \ddot{x}_{1}$ is the body heave acceleration which signifies the ride comfort and $\left(x_{2}-w\right)$ represents the wheel deflection which characterizes road holding quality.

Application of Newton's law to the quarter-car model shown in Fig. 2 yields the

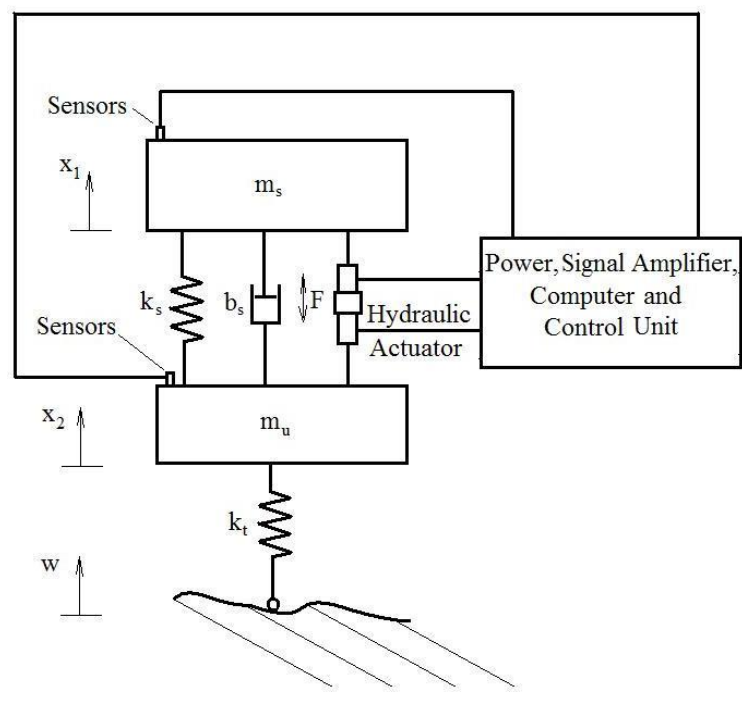

Fig. 2 Quarter Car Model

following nonlinear governing equations ${ }^{(20,22)}$ :

$$
\begin{aligned}
& \dot{x}_{1}=x_{3} \\
& \dot{x}_{2}=x_{4} \\
& m_{s} \dot{x}_{3}=k_{s}^{l}\left(x_{2}-x_{1}\right)+k_{s}^{n l}\left(x_{2}-x_{1}\right)^{3}
\end{aligned}
$$




$$
\begin{aligned}
& \quad+b_{s}^{l}\left(x_{4}-x_{3}\right)-b_{s}^{s y m}\left|x_{4}-x_{3}\right| \\
& +b_{s}^{n l} \sqrt{\left|x_{4}-x_{3}\right|} \operatorname{sgn}\left(x_{4}-x_{3}\right)-A x_{5} \\
& m_{u} \dot{x}_{4}=-k_{s}^{l}\left(x_{2}-x_{1}\right)-k_{s}^{n l}\left(x_{2}-x_{1}\right)^{3} \\
& \quad-b_{s}^{l}\left(x_{4}-x_{3}\right)+b_{s}^{s y m}\left|x_{4}-x_{3}\right| \\
& -b_{s}^{n l} \sqrt{\left|x_{4}-x_{3}\right|} \operatorname{sgn}\left(x_{4}-x_{3}\right)-k_{t}\left(x_{2}-w\right)+A x_{5} \\
& \dot{x}_{5}=\gamma \phi x_{6}-\beta x_{5}-\alpha A\left(x_{3}-x_{4}\right) \\
& \dot{x}_{6}=\frac{1}{\tau}\left(-x_{6}+u\right)
\end{aligned}
$$

where,

$$
\begin{aligned}
& \alpha=\frac{4 \beta_{e}}{V_{t}}, \beta=\alpha C_{t p}, \quad \gamma=C_{d} S \sqrt{\frac{1}{\rho}}, \quad \phi=\phi_{1} \times \phi_{2} \\
& \phi_{1}=\operatorname{sgn}\left[P_{s}-\operatorname{sgn}\left(x_{6}\right) x_{5}\right], \quad \phi_{2}=\sqrt{\left|P_{s}-\operatorname{sgn}\left(x_{6}\right) x_{5}\right|}
\end{aligned}
$$

Figure 3 represents the hydraulic actuator mounted in between the sprung and the unsprung masses. The hydraulic fluid flow rates $Q_{u}$ and $Q_{l}$ into the upper and lower chambers of the cylinder determines the actuator force generated.

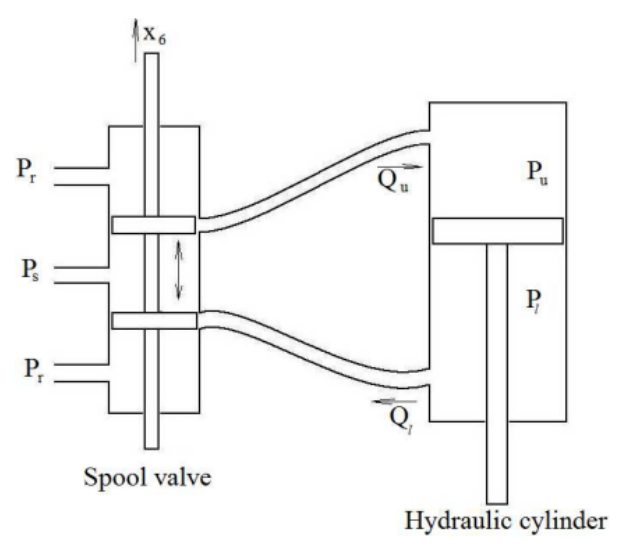

Fig. 3 Schematic of Double Acting Hydraulic Strut

The electro-hydraulic system is modelled as a firstorder dynamic system with a time constant $\tau$. Supply voltage of range $\pm 10 \mathrm{~V}$ is supplied to the servo-valves as control input to limit the suspension travel to $\pm 10 \mathrm{~cm}^{(23)}$.

$A$ is the area of the piston, $x_{3}$ and $x_{4}$ are vertical velocities of the sprung and unsprung masses respectively, $x_{5}$ is the pressure drop across the piston, $x_{6}$ is the servo-valve displacement, $P_{s}$ is the supply pressure into the hydraulic cylinder, $P_{r}$ is return pressure from the hydraulic cylinder, $P_{u}$ and $P_{l}$ are the oil pressure in the upper and lower portion of the cylinder. $V_{t}$ is the total actuator volume, $\beta_{e}$ is the effective bulk modulus of the system, $\Phi$ is the hydraulic load flow, $C_{t p}$ is the total leakage coefficient of the piston, $C_{d}$ is the discharge coefficient, $S$ is the spool-valve area gradient and $\rho$ is the hydraulic fluid density.

The suspension spring and damping forces have linear and nonlinear components. Spring constant, $k_{s}^{l}$, damping coefficient $b_{s}^{l}$, which affect the spring force and damping force in linear manner, $b_{s}^{s y m}$ contributes an asymmetric characteristics to the overall, behaviour of the damper, $k_{s}^{n l}$ and $b_{s}^{n l}$ are responsible for the nonlinear components of the spring and damper forces respectively.

\subsection{Road Disturbance Input Model}

The performance of the suspension system is evaluated at the vehicle travelling speed of $40 \mathrm{~km} / \mathrm{h}$ in the presence of a road disturbance input with sinusoidal profile, wavelength of $5 \mathrm{~m}$ and amplitude of $7 \mathrm{~cm}$. The profile of the hump is modeled by Equation 7 and Figure 4 and 5 .

$w(t)=\left\{\begin{array}{lc}\frac{a_{1}}{2}\left(1-\cos \frac{2 \pi V t}{\lambda}\right) & 1 \leq t \leq 1.25 \\ \frac{a_{1}}{2}\left(1-\cos \frac{2 \pi V t}{\lambda}\right) & 3 \leq t \leq 3.25 \\ 0 & \text { otherwise }\end{array}\right.$

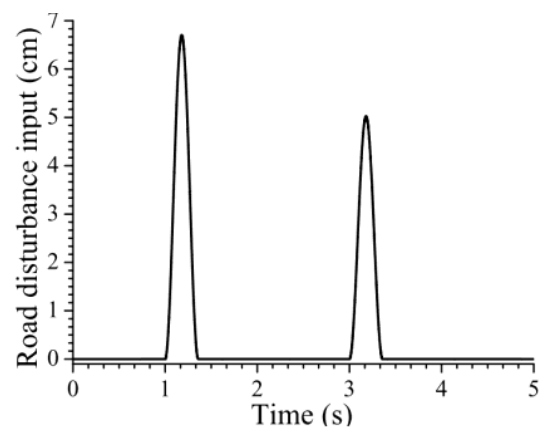

Fig. 4 Road Disturbance Input Profile

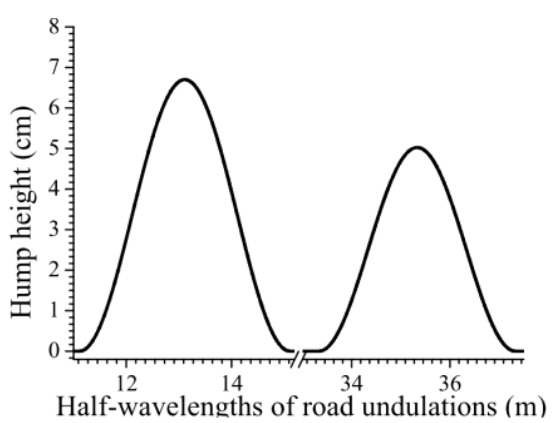

Fig. 5 Lateral View of the Road Disturbance Input Profile 
where a is the bump height, $V$ is the vehicle's velocity in straight line and $\lambda$ is the half wavelength of the sinusoidal road undulation. The values for the system parameters are provided in Table 1.

Table 1 Parameters of the Quarter-Car Model

\begin{tabular}{|c|c|}
\hline Parameters & Value \\
\hline Sprung mass, $m_{s}$ & $290 \mathrm{~kg}$ \\
\hline Unsprung mass, $m_{u}$ & $40 \mathrm{~kg}$ \\
\hline Tyre stiffness, $k_{t}$ & $1.9 \times 10^{5} \mathrm{~N} / \mathrm{m}$ \\
\hline Piston Area, $A$ & $3.35 \times 10^{-4} \mathrm{~m}^{2}$ \\
\hline Actuator Time constant, $\tau$ & $3.33 \times 10^{-2} \mathrm{sec}$ \\
\hline Supply Pressure, $P$ & $10,342,500 \mathrm{~Pa}$ \\
\hline Disturbance half wavelength, $\lambda$ & $2 m$ each \\
\hline Suspension stiffness (linear), $k_{s}^{l}$ & $2.35 \times 10^{4} \mathrm{~N} / \mathrm{m}$ \\
\hline Suspension stiffness (nonlinear), $k_{s}^{n l}$ & $2.35 \times 10^{6} \mathrm{~N} / \mathrm{m}$ \\
\hline Suspension damping (linear), $b_{s}^{l}$ & $700 N \mathrm{~s} / \mathrm{m}$ \\
\hline Suspension damping (nonlinear), $b_{s}^{n l}$ & $400 N \mathrm{~s} / \mathrm{m}$ \\
\hline Suspension damping (asymetrical), $b_{s}^{\text {sym }}$ & $400 N s / m$ \\
\hline Actuator Parameter, $\alpha$ & $4.515 \times 10^{13}$ \\
\hline Actuator Parameter, $\beta$ & 1 \\
\hline Actuator Parameter, $\gamma$ & $1.545 \times 10^{9}$ \\
\hline
\end{tabular}

ii. Disturbance rejection: The controller should demonstrate good low frequency disturbance attenuation

iii. Good command following: The suspension travel response of the AVSS is examined in the presence of the deterministic road inputs shown in Figure 4. The controller should be able to keep the steady-state error as close to zero as possible.

iv. Suspension travel: is constrained to physical limits to avoid damages due to topping and bottoming. Thus it is not to exceed $\pm 0.1 \mathrm{~m}^{(7)}$

v. The control voltage is also limited to $\pm 10 \mathrm{~V}$.

vi. The maximum actuator force must be less than the static weight of the vehicle, that is $F_{\text {hyd }}<m_{s} g$.

vii. For good road holding the dynamic load that is transmitted through the road should not be larger than the static weight of the vehicle. This is normalized with the static weight of the vehicle.

viii. Ride comfort: This is quantified using the vehicle body acceleration in the vertical direction. The vertical acceleration of the vehicle body needs to be minimal for good ride comfort, especially within the low frequency band of 0.1 to $10 \mathrm{~Hz}$. The peak sprung mass acceleration: $\ddot{x}_{1}<4.5 \mathrm{~m} / \mathrm{s}^{2(24,25,26)}$.

\subsection{Optimal Trade-Off Among Performance Criteria}

The objective function employed in the optimisation algorithms is presented in Equation 8. It is designed to minimise the suspension travel, $y$, actuator force, $F$, sprung mass acceleration, $\ddot{x}_{1}$, actuator spool-valve displacement, 
$x_{6}$, control voltage, $u$, and wheel deflection, $\left(x_{2}-w\right)$. This way, ride comfort and road holding is improved while control voltage and actuator force is kept as small as possible.

$$
\begin{gathered}
J=\frac{1}{T} \int_{0}^{T}\left[\left(\frac{y}{y_{\max }}\right)^{2}+\left(\frac{F}{F_{\max }}\right)^{2}+\left(\frac{\ddot{x}_{1}}{\ddot{x}_{1 \max }}\right)^{2}+\left(\frac{\dot{x}_{6}}{\dot{x}_{6}}\right)^{2}\right. \\
\left.+\left(\frac{u}{u_{\max }}\right)^{2}+\left(\frac{x_{2}-w}{\left(x_{2}-w\right)_{\max }}\right)^{2}\right] d t
\end{gathered}
$$

\section{Controller Design}

Implementation of the PID-controlled arrangement carried out in the MATLAB/SIMULINK environment is shown in Figure 6. The desired controlled output, $y$ is the suspension travel. Although each controller must be tuned independently, changes due to any of the controller affects the overall performance of the system, thereby making it necessary to re-tune the other controllers too.

The PID-controlled signal consist of $K_{p}$ term which is proportional to the error signal $e, K_{i}$ which is proportional to the integral of the error signal and $K_{d}$ which is proportional to the derivative of the error signal. Therefore, the PID control law is given by:

$$
u(t)=K_{p} e(t)+K_{i} \int e(t) d t+K_{d} \frac{d}{d t} e(t)
$$

where

$$
e(t)=y_{d}(t)-y(t), \text { reference signal is set to }
$$

$y_{d}=0.01 \sin 2 \pi t$, therefore the objective is to design a control

law for $u(t)$ such that $e(t) \rightarrow 0$ as $t \rightarrow \infty$.

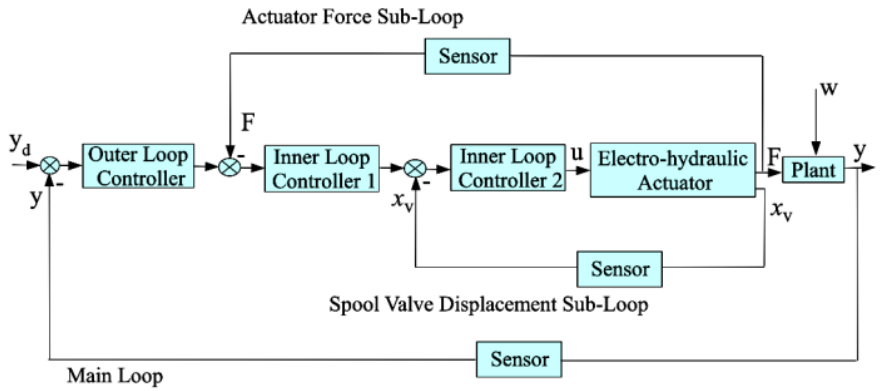

Fig. 6 AVSS Multi-Loop PID Control Architecture

The controllers were tuned using the Ziegler-Nichols tuning criterion on the basis of 0.25 decay ratio, and understanding of the system characteristics.
Further fine tuning was required, this was done manually since PID controllers tend to generate too high control inputs leading to saturation ${ }^{(27)}$. Table 2 presents the selected gains for the three controllers. The values for the integral and derivative component of the controllers were also marginal when compared to those of the proportional gains.

Table 2 PID Tuning Parameters

\begin{tabular}{|l|c|c|c|}
\hline \multirow{2}{*}{} & $K_{p}$ & $K_{i}$ & $K_{d}$ \\
\cline { 2 - 4 } & $-9.01748 \times 10^{3}$ & 13.3 & $1 \times 10^{-9}$ \\
\hline Main loop & 125.5 & 0.103 & $1 \times 10^{-3}$ \\
\hline $\begin{array}{l}\text { Spool-valve } \\
\text { displacement } \\
\text { sub-loop }\end{array}$ & $2.89 \times 10^{-4}$ & $3 \times 10^{-13}$ & $1 \times 10^{-10}$ \\
\hline $\begin{array}{l}\text { Actuator force } \\
\text { sub-loop }\end{array}$ & \multicolumn{3}{|c}{} \\
\hline
\end{tabular}

\section{Results and Discussion}

The control problem being solved was set up as a disturbance rejection and reference tracking problem. The reference input was $y_{d}=0.01 \sin 2 \pi t$. The disturbance input consisted of the twin humps shown in Figures 4 and 5 . The control objective being to minimise or eliminate deviation from the pre-set suspension travel value in spite of the disturbance input. The vehicle velocity was $40 \mathrm{~km} / \mathrm{h}$ and numerical simulations for the PID-controlled system was carried out with a sampling frequency of $1 \mathrm{kHz}$.

The actuator force generated was as a variable but preset control input of \pm l0Volts was supplied to the solenoid valve of the electrohydraulic actuator in response to the disturbance input.

Time histories of the AVSS's response are combined into Figure 7; where SVD stands for spool-valve displacement, AF represents actuator force, RDI represents road disturbance input, $\mathrm{CV}$ represents control voltage, NWDL represents normalized wheel dynamic load, ST represents suspension travel and BA represents vehicle body acceleration.

The range of values for the spool-valve displacement, control voltage and the suspension travel are well below the maximum allowable limits of $1 \mathrm{~cm}, 10$ volts and $10 \mathrm{~cm}$ 
respectively. The effect of the road disturbance input is clear but the controllers were able to return the responses back to tracking the sinusoidal referance input. intermittently at the points where the amplitudes of the road disturbance input was high. The maximum limits of the control input and the actuator force were also reached at these points.

The close reference tracking was distorted

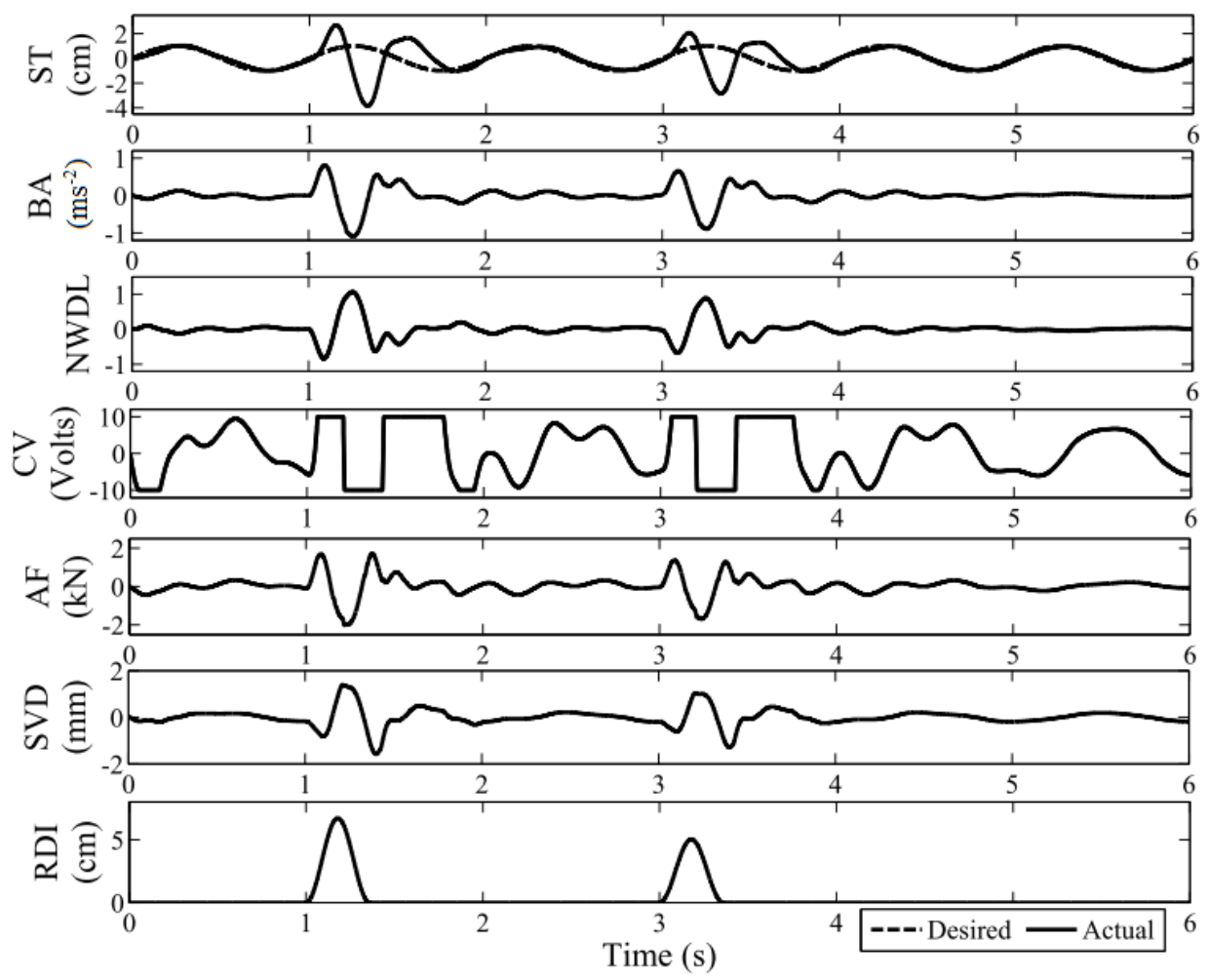

Fig. 7 Time History of the AVSS Responses to Deterministic Road Excitation and Reference Tracking for Suspension Travel

Figure 8 shows the tracking performances more clearly for both road conditions. The plot shows that the order of magnitude of the tracking error was millimetres except at the points where the amplitudes of the road disturbance input were high.

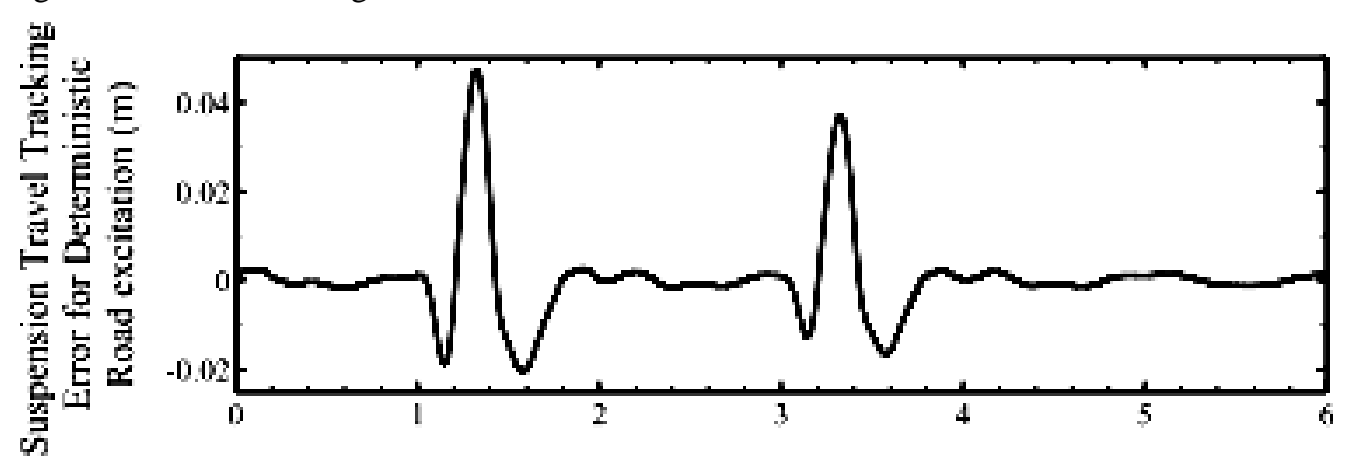

Fig. 8 Reference Tracking Error Plot for Suspension Travel

\section{Conclusions}

PID controller has been designed for a nonlinear AVSS application. Two inner PID control loops have been employed to stabilize the actuator dynamics and ensure a reference tracking of a sinusoidal reference input of the suspension travel. All the responses were within the stipulated ranges except for the actuator force and control voltage which exceeded the range marginally at the instances of the road disturbance inputs.

The popularity of PID control in terms of industrial application can not be ignored, its structure and its tuning is 
relatively simpler thus making it more readily applicable in cases where multiple or cascaded feedback control loops are required.

This paper has demonstrated that introducing additional PID control loop, increases the tuning options and assists in stabilising the actuator dynamics. As a consequence, the number of elements to be tuned is increased and this may be cumbersome unless some autotuning method is adopted.

\section{References}

(1) B. L. J. Gysen, J. J. H. Paulides, J. L. G. Janssen, and E. A. Lomonova: "Active electromagnetic suspension system for improved vehicle dynamics. IEEE Transactions on Vehicular Technology, Vol. 59, No. 3, pp. 1156-1163, Mar. 2010.

(2) G. Koch, O. Fritsch, and B. Lohmann. "Potential of low bandwidth active suspension control with continuously variable damper". In Proceedings of the 17th World Congress, The International Federation of Automatic Control (IFAC), Seoul, South Korea, pages 3392-3397, Jul.2008.

(3) S. Chantranuwathana and H. Peng. "Adaptive robust force control for vehicle active suspensions". International Journal of Adaptive Control and Signal Processing, Vol. 18, No. 2, pp.83-102, Mar.2004.

(4) O. A. Dahunsi, J. O. Pedro, and O. T. Nyandoro. "System identification and neural network based PID control of servo-hydraulic vehicle suspension systems". Transactions of the South African Institute of Electrical Engineersion (SAIEE), Africa Research Journal (ARJ), Vol. 101, No. 3, pp. 93-105, Sept. 2010.

(5) J. E. D. Ekoru, O. A. Dahunsi, and J. O. Pedro. "PID control of a nonlinear half-car active suspension via force feedback". In Proceedings of the 2011 IEEE AFRICON, Livingstone, Zambia, 2011.

(6) M. M. Fateh and S. S. Alavi. "Impedance control of an active suspension system". Mechatronics, Vol. 19, No. 1, pp.134-140, Feb. 2005.

(7) I. Fialho and G. J. Balas. Road adaptive active suspension using linear parameter-varying gain-scheduling. IEEE Transactions on Control Systems Technology, 10(1):43-54, Jan. 2002.

(8) B. Ayalew and B. T. Kulakowski. Modeling supply and return line dynamics for an electro-hydraulic actuation system. ISA Transactions, 44(3):329-343,
Jun. 2005.

(9) P. Y. Li and Q. Yuan. Flux observer for spool displacement sensing in self-sensing push-pull solenoids. In Proceedings of the 6th International Conference on Fluid Power Transmission and Control (ICFP 2005), pages 1-5, Hanzhou, China, Mar. 2005.

(10) J. Cao, H. Liu, P. Li, and D. Brown. "State of the art in vehicle active suspension adaptive control systems based on intelligent methodologies". IEEE Transactions of Intelligent Transportation Systems, Vol. 9, no. 3, pp.392-405, Sept. 2008.

(11) D. Cao, X. Song, and M. Ahmadian. "Editor's perspectives: Road vehicle suspension design, dynamics and control". Vehicle System Dynamics, Vol. 49, No. 1-2, pp.3-28, Jan.-Feb. 2011.

(12) C. Kaddissi, M. Saad, and J. P. Kenne. "Interlaced backstepping and integrator forwarding for nonlinear control of an electrohydraulic active suspension". Journal of Vibration and Control, Vol. 15, No. 1, pp.101-131, Jan. 2009.

(13) J. Seo, R. Venogopal, and J. P. Kenne. "Feedback linearization based control of a rotational hydraulic drive". Control Engineering Practice, Vol. 15, No. 12, pp.1495-1507, Dec. 2007.

(14) T. L. Chien, C. C. Chen, M. C. Tsai, and Y. C. Chen. "Almost disturbance decoupling and tracking control for multi-input multi-output non-linear uncertain systems: Application to a half-car active suspension system". Proceedings of the Institute of Mechanical Engineers, Part I: Journal of Systems and Control Engineering, Vol. 223, No. 2, pp.215-227, Mar. 2009.

(15) L. Giovanni. "Predictive feedback control: An alternative to proportional-integral-derivative control". Proceedings of the Institute of Mechanical Engineers, Part I: Journal of Systems and Control Engineering, Vol. 223, No. 7, pp.901-917, Jul. 2009.

(16) K. H. Ang, G. Chong, and Y. Li. "PID control system analysis, design, and technology". IEEE Transactions on Control Systems Technology, Vol. 13, No.4, pp.559-576, Jul. 2005.

(17) E. N. Goncalves, R. M. Palhares, and R. H. C. Takahashi. "A novel approach for $\mathrm{H}_{2} / \mathrm{H}_{\infty}$ robust PID synthesis for uncertain systems". Journal of Process Control, 18(1):19-26, Jan.2008.

(18) Z. Gao. "From linear to nonlinear control means: A 
practical progression". ISA Transactions, Vol. 41, No.2, pp.177-189, Apr. 2002.

(19) M. Dangor, O. A. Dahunsi, J. O. Pedro, and M. M. Ali. "Evolutionary Algorithm-based PID Controller Tuning for Nonlinear Quarter-Car Electrohydraulic Vehicle Suspensions" Nonlinear dynamics, Vol. 78(4) : 2795-2810, Dec. 2014.

(20) J. O. Pedro, M. Dangor, O. A. Dahunsi and M. M. Ali. "Intelligent Feedback Linearization Control of Nonlinear Electrohydraulic Suspension Systems Using Particle Swarm ptimization" Applied Soft Computing", Vol. 24, Nov. 2014

(21) S. Cetin and A. V. Akkaya. "Simulation and hybrid fuzzy-PID control for positioning of a hydraulic system". Nonlinear Dynamics, Vol. 61, No. 3, pp.465-476, Nov. 2010.

(22) J. O. Pedro, M. Dangor, O. A. Dahunsi, and M. M. Ali. "CRS and PS - optimised PID controller for nonlinear, electrohydraulic suspension systems". In Proceedings of the 9th Asian Control Conference, pp. 1251-1257, Istanbul, Turkey, June. 2013.

(23) P. Gaspar, I. Szaszi, and J. Bokor. "Active suspension design using linear parameter varying control". International Journal of Autonomous Systems (IJVAS), Vol. 1, No. 2, pp. 206-221, Jun. 2003.

(24) M. J. Griffin. "Discomfort from feeling vehicle vibration". Vehicle Systems Dynamics, Vol. 45, No. 7-8, pp. 679-698, Jul.-Aug. 2007.

(25) European Commission. "Directive 2002/44/EC of the European Parliament and the Council of 25 June 2002 on the minimum health and safety requirements regarding the exposure of workers to the risk arising from physical agents (vibration)". Official Journal of the European Communities, Luxembourg, 2002.

(26) ISO 2631. "Mechanical Vibration and Shock Evaluation of Human Exposure to Whole-Body Vibration - Part 1: General Requirements". International Organization for Standardization, Geneva, Switzerland, 2003.

(27) K. J. Astrom and T. Hagglund. "The future of PID control". Control Engineering Practice, Vol. 9, No. 11, pp.1163-1175, Nov. 2001. 